Proposta de alteração do layout de um centro de distribuição de produtos alimentícios utilizando simulação de cenários e o método de processo de análise hierárquica (AHP)

\title{
Proposal of layout modification in a food products' distribution center using scenario simulation and the analytic hierarchy process method (AHP)
}

Daniéli Bonecher ${ }^{1}$, Universidade Federal de Santa Catarina, Depto. Engenharias da Mobilidade André Loch Carmona ${ }^{2}$, Universidade Federal de Santa Catarina, Depto. Engenharias da Mobilidade Francielly Hedler Staudt ${ }^{3}$, Universidade Federal de Santa Catarina, Depto. Engenharias da Mobilidade Luisa Mafra Oliveira ${ }^{4}$, Universidade Federal de Santa Catarina, Depto. Engenharias da Mobilidade

\section{RESUMO}

O centro de distribuição compreende as principais atividades logísticas por estar envolvido diretamente com recebimento, expedição de materiais, estocagem e distribuição. Um layout eficiente pode trazer muitos benefícios para a empresa. Desta forma, o objetivo desse trabalho é propor uma alteração no layout (utilizando simulação de cenários) do centro de distribuição de uma empresa multinacional do setor de alimentos e bebidas, levando em consideração como principal critério o aumento da capacidade de armazenagem. Para isto, realizou-se um levantamento da situação atual e das necessidades da empresa, para simular diferentes cenários de layout verticalizados utilizando o software SketchUp ${ }^{\circledR}$. Para os três cenários que apresentam layouts com as maiores capacidades de armazenagem analisam-se suas vantagens e desvantagens utilizando dados quantitativos. Para auxiliar os gestores na definição do melhor cenário utilizou-se o método de análise multicritério Analytic Hierarchy Process (AHP), resultando no cenário do layout 1 como a melhor solução a ser implantada no centro de distribuição.

Palavras-Chave: Arranjo físico. Processo de análise hierárquica. Cenários. Centro de Distribuição.
Editor Responsável: $\quad$ Prof. Dr. Hermes Moretti Ribeiro da Silva

\section{ABSTRACT}

The distribution center comprises the main logistics activities because it is directly involved in the receiving, dispatching, storage and distribution of materials. An efficient layout can bring many benefits to the company. In this way, the objective of this work is to propose a layout modification (using scenarios simulation) in a multinational company's distribution center in its food and beverage sector, considering the increase of storage capacity as the main criterion. To do this, the current situation and the needs of the company were determined, and different vertical layout scenarios using SketchUp ${ }^{\circledR}$ software were simulated. For the three scenarios presenting layouts with the greatest storage capacities, their advantages and disadvantages were analyzed using quantitative data. In order to assist managers in defining the best scenario, the Analytic Hierarchy Process (AHP) method was used, resulting in the layout 1 scenario being perceived as the best solution to be implemented in the distribution center.

\section{Keywords: Layout. Analytic Hierarchy Process. Scenarios. Distribution Center.}

3.Rua Dona Francisca, 8300, Bloco U, Zona Industrial Norte, CEP 89.219-600, Joinville/ SC, francielly.hedler.staudt@ufsc.br; 1. danielibonecher@hotmail.com; 2. andre.cloch@hotmail.com; 4. luisa.maoli@gmail.com

BONECHER, D.; CARMONA, A.L.; STAUDT, F.H.; OLIVEIRA, L.M. Proposta de alteração do layout de um centro de distribuição de produtos alimentícios utilizando simulação de cenários e o método de processo de análise hierárquica (AHP). GEPROS. Gestão da Produção, Operações e Sistemas, v. 15, n. 2, p. 58 - 90, 2020. DOI: 10.15675/gepros.v15i2.2430 
Proposta de alteração do layout de um centro de distribuição de produtos alimentícios utilizando simulação de cenários e o método de processo de análise hierárquica (AHP)

\section{INTRODUÇÃO}

Considerando o atual ambiente econômico brasileiro, as empresas têm buscado constantemente aperfeiçoar suas práticas logísticas no sentido de acompanhar as mudanças tecnológicas demandadas pelo mercado (PARDINI; MATUCK, 2012). Os armazéns são muito importantes para o sucesso do negócio, pois eles têm um papel crítico e intermediário entre os membros da cadeia de suprimentos, afetando os custos e serviços (FABER et al., 2013). Diariamente novas tecnologias para práticas operacionais são desenvolvidas, com o objetivo de ampliar a produtividade e garantir a excelência dos armazéns. Se utilizada de forma adequada, a armazenagem pode se constituir em uma importante vantagem competitiva (MELO; OLIVEIRA, 2006).

Segundo Zhang et al. (2017) um layout de armazém eficaz pode reduzir os custos operacionais. Erros no projeto de layout podem gerar interrupções no fornecimento, levando à insatisfação do consumidor interno e externo, atrasos na produção, estoques confusos e desnecessários, além de altos custos relacionados à ineficiência da criação de sinergia entre o conjunto do arranjo físico (ROSA, 2014). Assim, um armazém com layout apropriado e operações efetivas tem a sua eficiência aumentada (JERMSITTIPARSERT; SUTDUEAN; SRIYAKUL, 2019), gerando economias em múltiplos aspectos, seja devido à distribuição dos instrumentos de trabalho, dos pontos de armazenamento ou ao fator humano envolvido (HUDSON; HADDAD, 2014).

Contudo, Cardona et al. (2015) afirmam que um mesmo layout 'ótimo' terá um custo operacional diferente dependendo da sua localização, visto que alguns países têm baixos preços de terra e alto custo de manuseio de material, enquanto outros têm altos preços de terra e baixo custo de manuseio de material. Assim, a definição de um layout é dependente do problema, ou seja, não há melhor design, metodologia ou política para todos os problemas em consideração (HUERTAS; RAMÍREZ; SALAZAR, 2007). Por este motivo, os estudos de layout continuam sendo um tema importante na área da logística. Torna-se essencial avaliar todos os requisitos em cada situação para definir o layout 'ótimo'.

Dentro deste contexto, este artigo analisa a alteração do layout de um Centro de Distribuição (CD) de produtos alimentícios. A empresa em estudo tem uma projeção de aumento da demanda no ano de 2019 de uma nova linha de produtos, gerando a necessidade 
Proposta de alteração do layout de um centro de distribuição de produtos alimentícios utilizando simulação de cenários e o método de processo de análise hierárquica (AHP)

de expansão da capacidade do seu centro de distribuição. Segundo Bai (2019) o layout de centros de distribuição, incluindo suas atividades (armazenagem, separação, embalagem e outras) devem estar de acordo com a estratégia de vendas da empresa. Desta forma, o resultado do estudo busca expandir a capacidade do CD de acordo com a estratégia de operação da empresa, avaliando diversas restrições físicas e objetivos conflitantes. Para auxiliar nesta análise, o método AHP foi utilizado para auxiliar os gestores na decisão da melhor alternativa de layout, demonstrando a viabilidade de uso da ferramenta para este fim.

Para o alcance do objetivo, além desta seção introdutória o artigo tem mais cinco seções e as referências bibliográficas ao final. Após a apresentação da fundamentação teórica sobre desenvolvimentos de layout em armazéns e o método multicritério de apoio à decisão AHP (Analytic Hierarchy Process - Processo de Análise Hierárquica) (seção 2), será caracterizada a empresa e realizada um levantamento das necessidades operacionais do CD (seção 3). Após isso, na seção 4 são simulados diferentes modelos de layout utilizando o software SketchUp ${ }^{\circledR}$ e os diferentes cenários são comparados por gestores da empresa utilizando o método AHP. O trabalho finaliza com as considerações finais na seção 5.

\section{REFERENCIAL TEÓRICO}

\subsection{Tipos de Layout de armazéns}

Visto que a atividade de armazenagem pode ser entendida como a guarda de mercadorias que devem ser movimentadas de forma rápida, eficiente e segura, o objetivo final no planejamento de todos os tipos de áreas funcionais do CD é melhorar a eficiência operacional global e maximizar os benefícios econômicos (BAI, 2019).

A configuração de um layout determina a forma de organizar as máquinas e departamentos da empresa de modo a minimizar o tempo de ciclo do produto dentro da fábrica ou centro de distribuição, gerando a maximização do volume de negócios e da capacidade produtiva a partir da redução de distâncias percorridas (ROSA et al., 2014).

O principal tipo de layout utilizado na grande maioria dos armazéns ao redor do mundo é o denominado "layout tradicional", caracterizado pelo posicionamento de corredores paralelos, ortogonais às paredes (CARDONA et al., 2015). A Figura 1 demonstra algumas configurações possíveis dos layouts tradicionais, em que P\&D significa o ponto inicial e final 
Proposta de alteração do layout de um centro de distribuição de produtos alimentícios utilizando simulação de cenários e o método de processo de análise hierárquica (AHP)

do processo de picking (separação de pedidos), que fica localizado junto às docas de entrada e saída de produtos. Verifica-se que, dentre as configurações possíveis pode ser inserido um corredor intermediário (layouts b e c da Figura 1), dividindo o comprimento das estruturas de armazenagem em duas. O principal objetivo destes corredores é a redução no tempo de viagem na separação dos pedidos, um dos principais objetivos dos estudos de layout, juntamente com aumento da utilização do espaço físico (HUERTAS; RAMÍREZ; SALAZAR, 2007).

Somente em 2009 aparecem outros layouts não tradicionais que ganham atenção da comunidade acadêmica (CARDONA et al., 2015), e os principais deles são o layout espinha de peixe (fishbone layout) e o layout em "Y" (flying-V layout) (POHL; MELLER; GUE, 2011).

Figura 1 - Exemplos de layouts tradicionais (a) com corredores paralelos na direção das docas de entrada/saída de produtos, (b) com corredores paralelos às docas, porém divididos por um corredor intermediário, (c) com corredores ortogonais às docas e divididos por um corredor intermediário.

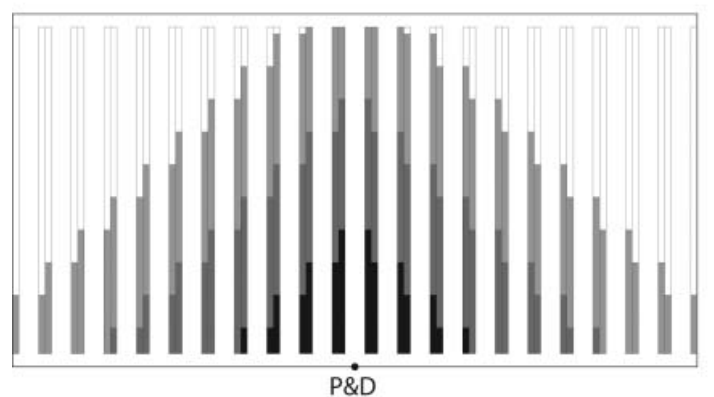

(a)

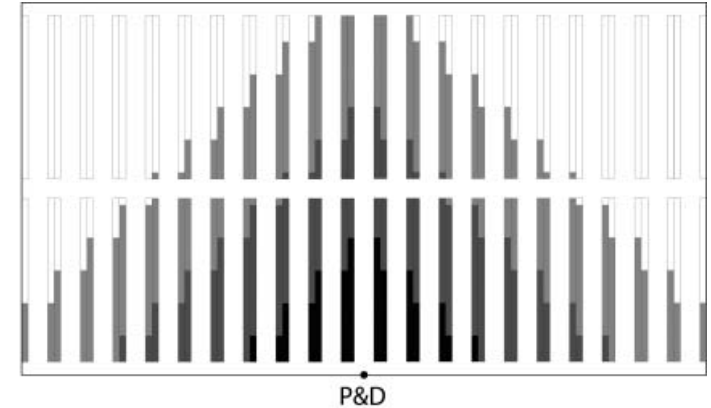

(b)

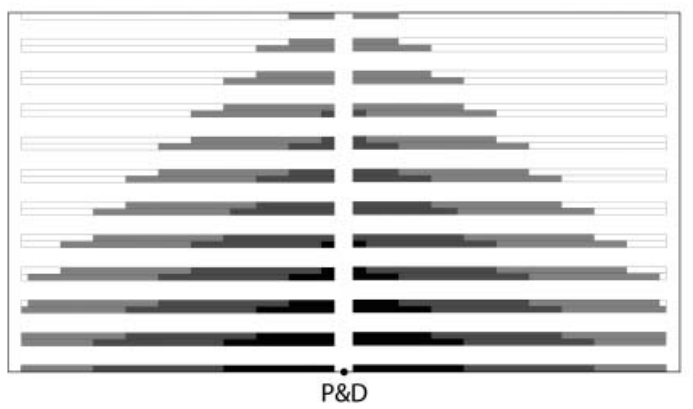

(c)

Fonte: Pohl, Meller e Gue (2011).

O layout em Y possui dois corredores na diagonal que se encontram em um ponto comum, de onde parte um corredor vertical (ver Figura 2). Esta organização cria uma linha GEPROS. Gestão da Produção, Operações e Sistemas, v. 15, nº 2, p. 58 - 90, 2020 
Proposta de alteração do layout de um centro de distribuição de produtos alimentícios utilizando simulação de cenários e o método de processo de análise hierárquica (AHP)

reta durante o percurso de-para em alguns locais de separação. Quando comparado aos layouts tradicionais, Pohl, Meller e Gue (2011) apontam que este modelo apresenta uma redução no tempo de separação de pedidos de aproximadamente $10 \%$.

Já o layout espinha de peixe (Figura 3) tem dois corredores transversais diagonais e os corredores nas zonas inferiores são perpendiculares aos corredores nas zonas superiores. Assim, os corredores formam um ângulo de $90^{\circ}$ entre si, sendo chamado então de corredores em "V". A melhoria no desempenho do layout é conseguida tornando as distâncias de deslocamento mais próximas de serem "euclidianas", em vez dos caminhos retilíneos que devem ser percorridos em layouts tradicionais (CARDONA et al., 2015).

Figura 2 - Exemplo de layout em Y.

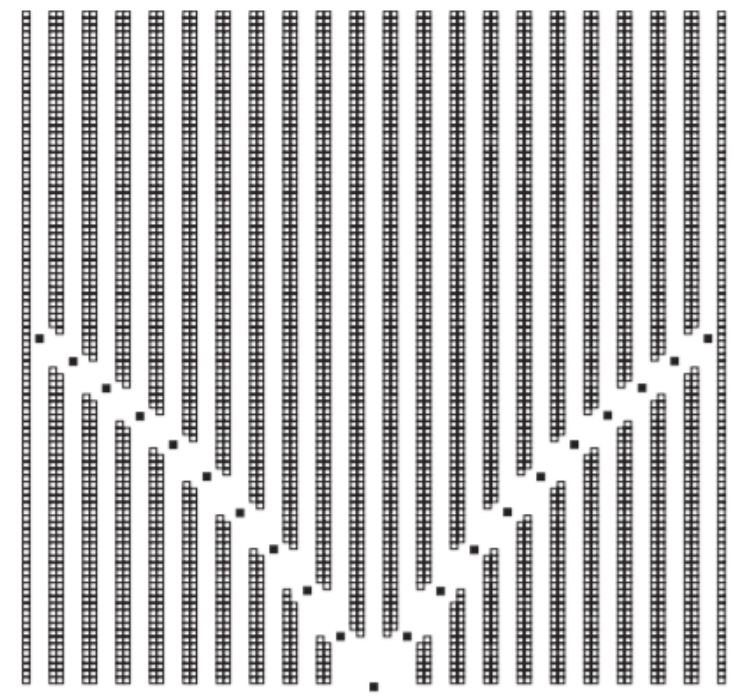

Fonte: Pohl, Meller e Gue (2011).

Figura 3 - Layout espinha de peixe.

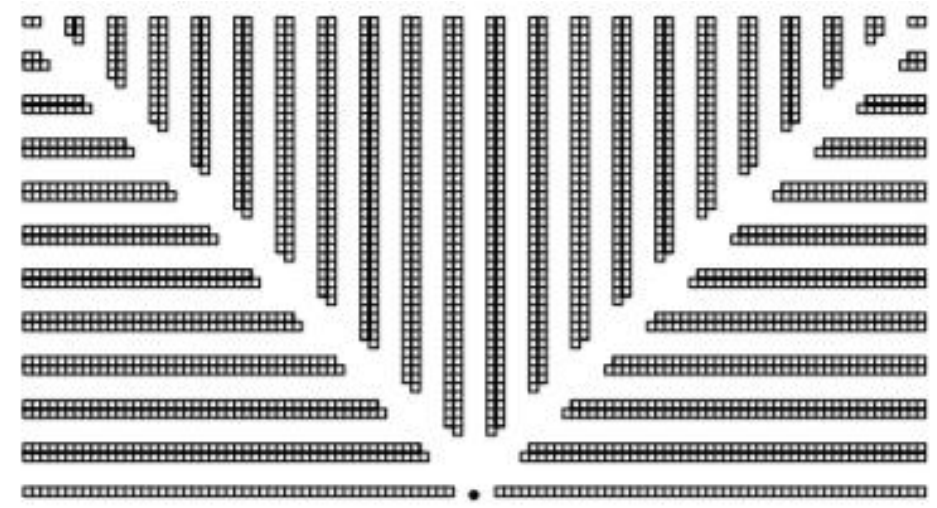

Fonte: Pohl, Meller e Gue (2011).

GEPROS. Gestão da Produção, Operações e Sistemas, v. 15, nº 2, p. 58 - 90, 2020. 
Proposta de alteração do layout de um centro de distribuição de produtos alimentícios utilizando simulação de cenários e o método de processo de análise hierárquica (AHP)

Gue e Meller (2009), autores do primeiro estudo comprovando os benefícios destes novos layouts, afirmam que o tempo de trajeto em um armazém com o layout espinha de peixe é cerca de 20,4\% menor que um armazém tradicional em paralelo com o mesmo comprimento total de corredores de separação.

A definição de layouts de armazéns continua sendo um tema atual (BAI, 2019; DERHAMI; SMITH; GUE, 2019; SIREGAR; TARIGAN; NASUTION, 2018; ROSA; STEINER; COLMENERO, 2015a), principalmente em função do aparecimento de novas tecnologias (BAKER; HALIM, 2007; CUSTODIO; MACHADO, 2020; ROY et al., 2012; WANG; CHEN; XIE, 2010; WEI, 2012) e de novos modelos de layout como os apresentados por Pohl, Meller e Gue (2011) (WANG et al., 2020).

$\mathrm{Na}$ próxima seção são apresentados alguns critérios primordiais relacionados à execução de uma proposta de layout.

\subsection{Desenvolvimento de layout de armazéns}

Algumas decisões típicas relacionadas à armazenagem de produtos são: a determinação do espaço de armazenagem, o layout do armazém e projetos de docas, a configuração do armazém, a disposição dos produtos no estoque de acordo com o tipo de produto, tipo de cliente ou rotatividade (MORABITO; IANNONI, 2007)

Para Peinado e Graeml (2007) a necessidade de tomar decisões referentes ao layout de uma empresa ocorre por diferentes razões, como a necessidade de expansão da capacidade produtiva, o elevado custo operacional causado pelo layout atual, a introdução de uma nova linha de produtos e a melhoria do ambiente de trabalho.

Ainda de acordo com Peinado e Graeml (2007), existem alguns princípios básicos que devem ser considerados no estudo do novo layout, sendo eles:

- Segurança: O projeto precisa ser executado a partir da planta de incêndio do armazém, de modo que as saídas e corredores de incêndio estejam claramente sinalizadas e com livre acesso. Todos os processos que representam alguma forma de perigo não devem ser acessíveis a pessoas não autorizadas.

- Economia de movimentos: O layout deve permitir um fluxo de produto eficiente, contemplando a minimização das distâncias percorridas pelo produto, pelas pessoas e pelos equipamentos de movimentação. 
Proposta de alteração do layout de um centro de distribuição de produtos alimentícios utilizando simulação de cenários e o método de processo de análise hierárquica (AHP)

- Flexibilidade de longo prazo: O layout deve possuir flexibilidade para ajustes a longo prazo, uma vez que a operação passe a ter novas necessidades futuramente.

- Princípio de progressividade: O layout deve possuir um sentido definido a ser percorrido pelo fluxo do produto, que evite retornos ou caminhos aleatórios.

- Uso de espaço: Deve-se buscar sempre a otimização do espaço disponível, assim o layout precisa ser desenvolvido de modo a utilizar a maior área possível para a armazenagem (levando em consideração a possibilidade de ocupação verticalizada) e área definida de maneira suficiente para execução das demais atividades.

A eficiência do armazém está diretamente ligada a distribuição dos produtos nas estruturas de armazenagem, uma vez que o tempo a ser utilizado para movimentar um produto depende sobretudo da sua localização e endereçamento. Em razão disso, a distribuição dos produtos deve ser definida a partir de um planejamento estratégico, Gonçalves e Cassel (2017) define os seguintes fatores a serem seguidos:

- O estoque de materiais que possuem maior giro deve ter fácil e rápido acesso, a fim de garantir economia de tempo para a operação.

- Os materiais de uma única classe devem ser armazenados em locais adjacentes, buscando facilitar a movimentação.

- Os estoques devem ser organizados agrupando os mesmos tipos de materiais e lotes, deve-se posicionar os produtos de acordo com o critério de movimentação adotado pela empresa, de modo a facilitar e reduzir o tempo da operação de separação.

- Materiais pesados e volumosos devem ser armazenados nas partes inferiores das estruturas de armazenagem, de modo a reduzir os riscos de acidentes e avarias e contribuir para a facilidade da movimentação.

- A disposição dos materiais deve possuir uma leitura rápida, sendo possível identificar os produtos pela sua etiqueta de identificação principal, geralmente anexa ao pallet.

Todos os requisitos apresentados são importantes questões a serem avaliadas em armazéns com quaisquer tipos produtos. Contudo, o armazenamento de alimentos é de extrema importância para a sociedade atual e exige alguns cuidados extras na definição do layout. 
Proposta de alteração do layout de um centro de distribuição de produtos alimentícios utilizando simulação de cenários e o método de processo de análise hierárquica (AHP)

De acordo com Machado (2000, p.8) o Ministério da Agricultura e do Abastecimento recomenda que a armazenagem de alimentos deve cumprir alguns requisitos, como os relacionados no Quadro 1.

Quadro 1 - Recomendações para armazenagem de produtos alimentícios.

\begin{tabular}{|c|c|}
\hline Requisito & Recomendação \\
\hline $\begin{array}{c}\text { Atender às } \\
\text { especificações } \\
\text { do fabricante }\end{array}$ & $\begin{array}{l}\text { - As instruções para a armazenagem, o prazo ou data de validade e a temperatura de } \\
\text { conservação, quando estabelecidas pelo fabricante e constantes dos rótulos, devem ser } \\
\text { rigorosamente respeitadas. Produtos em desacordo com os mesmos não devem ser } \\
\text { utilizados ou comercializados. } \\
\text { - As instruções sobre empilhamento, quando existentes, devem ser rigorosamente } \\
\text { respeitadas. }\end{array}$ \\
\hline $\begin{array}{c}\text { Disposição dos } \\
\text { produtos no } \\
\text { armazém }\end{array}$ & $\begin{array}{l}\text { - O armazenamento deve ser feito de tal forma, que não permita que a carga, matéria- } \\
\text { prima, embalagem ou produto, receba luz solar direta. } \\
\text { - Não armazenar alimentos junto a produtos químicos, de higiene, de limpeza e perfumaria, } \\
\text { para evitar contaminação ou impregnação com odores estranhos. }\end{array}$ \\
\hline $\begin{array}{c}\text { Manipulação dos } \\
\text { produtos }\end{array}$ & $\begin{array}{l}\text { - Os alimentos devem ser posicionados com utensílios apropriados exclusivos e após sua } \\
\text { utilização, as embalagens devem ser fechadas adequadamente. } \\
\text { - Alimentos que precisam ser transferidos de suas embalagens originais devem ser } \\
\text { acondicionados de forma que se mantenham protegidos, em contentores descartáveis ou } \\
\text { outro adequado para guarda de alimentos, devidamente higienizados. As informações do } \\
\text { rótulo devem ser transcritas em etiquetas. }\end{array}$ \\
\hline $\begin{array}{l}\text { Padrões físicos } \\
\text { do armazém }\end{array}$ & $\begin{array}{l}\text { - Alimentos ou recipientes com alimentos não devem estar em contato com o piso e sim } \\
\text { apoiados sobre estrados ou prateleiras de estantes. Jamais depositá-los diretamente sobre } \\
\text { o piso. } \\
\text { - As prateleiras devem ter afastamento mínimo de } 60 \mathrm{~cm} \text { do forro e } 35 \mathrm{~cm} \text { das paredes, } \\
\text { sempre que possível, sendo } 10 \mathrm{~cm} \text { o mínimo aceitável. } \\
\text { - Os estrados e prateleiras devem estar limpos e secos e em bom estado de conservação. } \\
\text { - Manter os pallets com matéria-prima ou embalagens, com afastamento mínimo de } 50 \mathrm{~cm} \\
\text { das paredes para evitar umidade e facilitar a limpeza, amostragem e movimentações, } \\
\text { controle de pragas e ações em caso de incêndio. } \\
\text { - Manter os pallets com afastamento de } 30 \mathrm{~cm} \text { entre si e } 20 \mathrm{~cm} \text { do piso. }\end{array}$ \\
\hline
\end{tabular}

Fonte: Adaptado de Machado (2000).

Em suma, a definição do layout ideal depende de um planejamento que contemple a avaliação de inúmeras alternativas para que possa ser escolhida a que maior tiver afinidade com o produto ou serviço que será desenvolvido (ROSA et al., 2014). Segundo Gu, Goetschalckx e McGinnis (2010) um bom modelo de avaliação de desempenho pode ajudar gestores a avaliar rapidamente muitas alternativas de design durante o estágio de projeto inicial.

Existem na literatura diversas metodologias de análise de decisão multicritério (MCDA) que auxiliam os gestores em tomada de decisões diversas. A principal característica 
Proposta de alteração do layout de um centro de distribuição de produtos alimentícios utilizando simulação de cenários e o método de processo de análise hierárquica (AHP)

do MCDA é auxiliar o decisor na análise de pelo menos duas alternativas cujo conjunto de alternativas apresenta diferentes critérios que normalmente são conflitantes entre si (ARAUJO; AMARAL, 2016). Um dos métodos presentes na literatura é o AHP (Analytic Hierarchy Process). "O AHP é uma das ferramentas de apoio ao processo decisório de múltiplos critérios com maior número de aplicações práticas reportadas na literatura e cujo âmbito de aplicação abrange áreas como de engenharia, da educação, médica, etc.”(ALVES; ALVES, 2014, p.14). Como o AHP será utilizado neste trabalho para a avaliação de diversas alternativas de layout formuladas, ele será apresentado em mais detalhes na próxima seção.

\subsection{Método AHP (Analytic Hierarchy Process)}

O método AHP foi desenvolvido por Thomas Saaty na década de 1970 nos EUA (SHIMIZU; 2006, p. 278). "Ele procura reproduzir o raciocínio humano em situações que envolvem complexidade e subjetividade por meio da comparação de elementos de um conjunto, baseando-se na percepção de analistas.” (RAMOS FILHO; ATAMANCZUK; MARÇAL, 2010, p. 145).

Apesar de ser um método mundialmente reconhecido há décadas, ainda existem pesquisas utilizando o processo AHP na resolução de problemas de tomada de decisão na logística (GUO; ZHANG, 2010; HO et al., 2012; YADAV; GARG; LUTHRA, 2020) assim como para problemas relacionados à armazenagem (ALVES; ALVES, 2014; CHAKRABORTY; MAJUMDER; SARKAR, 2011; HUANG; LIAO, 2012; ÖZCAN; ÇELEBI; ESNAF, 2011; ROSA; STEINER; COLMENERO, 2015b), o que demonstra a sua importância e aplicabilidade ainda nos dias atuais.

“A programação multicritério, por meio do processo AHP, é estruturada para tomada de decisão em ambientes complexos em que diversas variáveis ou critérios são considerados para a priorização e seleção de alternativas." (ROSA; STEINER; COLMENERO, 2015, p. 938). O processo AHP tem início pela estruturação do problema em uma hierarquia de critérios ou atributos, denominada estrutura hierárquica (Figura 4). Esta estrutura inicia com a definição do objetivo (primeiro nível), seguido dos critérios que serão avaliados no problema (segundo nível). Por último (terceiro nível), são verificadas todas as alternativas a serem avaliadas segundo os critérios estabelecidos.

Segundo Saaty e Vargas (2001) esse arranjo do problema em uma estrutura hierárquica como a da Figura 4 possibilita uma visualização gráfica do problema e orienta os GEPROS. Gestão da Produção, Operações e Sistemas, v. 15, nº 2, p. 58 - 90, 2020 
Proposta de alteração do layout de um centro de distribuição de produtos alimentícios utilizando simulação de cenários e o método de processo de análise hierárquica (AHP)

especialistas sobre as comparações par a par, ou paritárias, que devem ser feitas para que se obtenham as prioridades de um atributo (ou sub atributo) em relação a outro.

A partir do momento em que essa hierarquia lógica é construída, a etapa seguinte do processo AHP é avaliar sistematicamente as alternativas por meio da comparação, duas a duas, de cada um dos critérios ou atributos.

Figura 4 - Exemplo de estrutura hierárquica.

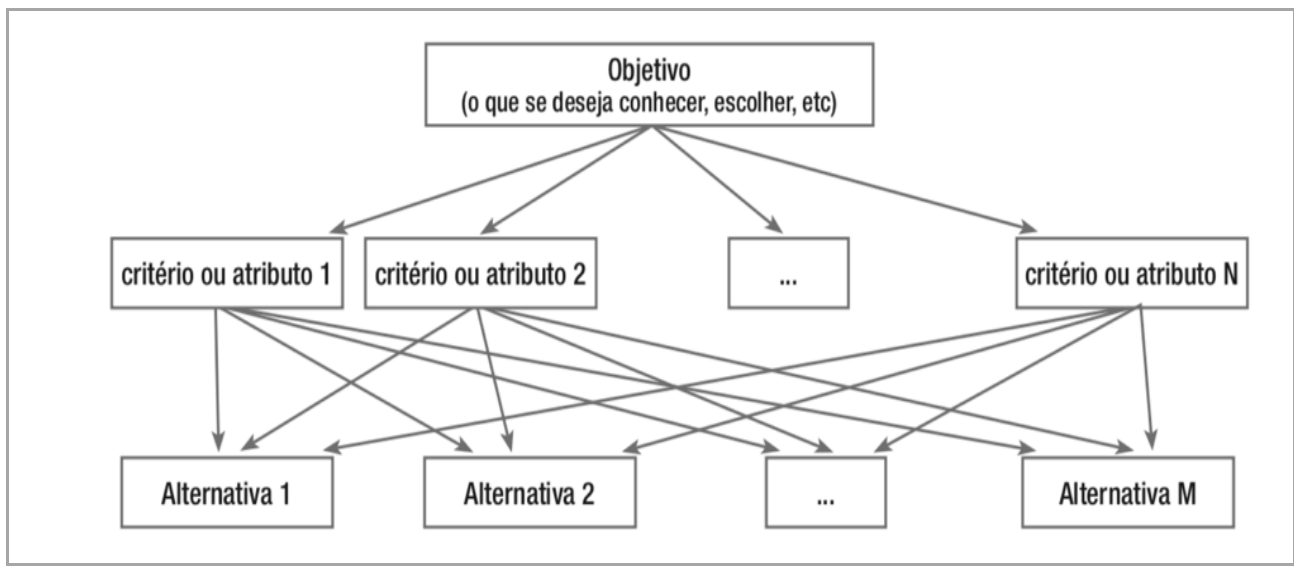

Fonte: Saaty (1980).

Essa comparação pode utilizar dados concretos das alternativas ou julgamentos humanos como forma de informação (SAATY, 1980).

Ribeiro e Costa (1999, p. 8) apresentam as tarefas a serem realizadas durante o procedimento de análise pareada:

- Seleção dos julgadores e definição dos métodos para a realização dos julgamentos paritários (par a par) ou binários, nos quais são avaliados cada parâmetro e o desempenho de cada alternativa baseada nos mesmos;

- Síntese dos dados levantados nos julgamentos, mediante cálculo da prioridade de cada alternativa em relação ao foco ou objetivo principal.

O padrão mais utilizado para avaliar as alternativas por meio de comparação é a escala fundamental de Saaty (1980) (Quadro 2), onde o valor 1 significa que os critérios possuem a mesma importância e podem ir até o valor 9 que significa que um critério tem importância absoluta em relação ao outro. 
Proposta de alteração do layout de um centro de distribuição de produtos alimentícios utilizando simulação de cenários e o método de processo de análise hierárquica (AHP)

Quadro 2 - Escala fundamental de Saaty.

\begin{tabular}{|c|c|l|}
\hline \multicolumn{3}{|c|}{ Escala fundamental de Saaty } \\
\hline $\begin{array}{c}\text { Intensidade de } \\
\text { Importância }\end{array}$ & Definição & \multicolumn{1}{c|}{ Explicação } \\
\hline 1 & Igual importância & As duas atividades contribuem igualmente para o objetivo \\
\hline 3 & $\begin{array}{c}\text { Importância pequena de uma } \\
\text { sobre a outra }\end{array}$ & $\begin{array}{l}\text { A experiência e o juízo favorecem uma atividade em relação a } \\
\text { outra }\end{array}$ \\
\hline 5 & $\begin{array}{c}\text { Importância grande ou } \\
\text { essencial }\end{array}$ & $\begin{array}{l}\text { A experiência ou juízo favorece fortemente uma atividade em } \\
\text { relação a outra }\end{array}$ \\
\hline 7 & $\begin{array}{c}\text { Importância muito grande ou } \\
\text { demonstrada }\end{array}$ & $\begin{array}{l}\text { Uma atividade é muito fortemente favorecida em relação a } \\
\text { outra. Pode ser demonstrada na prática }\end{array}$ \\
\hline 9 & $\begin{array}{c}\text { Importância absoluta } \\
\text { A evidência favorece uma atividade em relação a outra, com o } \\
\text { mais alto grau de segurança }\end{array}$ \\
\hline $2,4,6,8$ & Valores Intermediários & $\begin{array}{l}\text { Quando se procura uma condição de compromisso entre duas } \\
\text { definições }\end{array}$ \\
\hline
\end{tabular}

Fonte: Saaty (1980).

Contudo, "mesmo que os profissionais julgadores possuam conhecimento e experiência, podem ocorrer inconsistências principalmente quando existir um grande número de comparações a serem feitas no modelo.” (ALVES; ALVES, 2014, p.17). Portanto, para validar os julgamentos e assegurar que eles são consistentes Saaty e Vargas (2001) propõe o cálculo do índice de consistência (IC) conforme Equação 1.

$$
I C=\frac{\left|\left(\lambda_{\max }-n\right)\right|}{n-1}
$$

Em que $n$ representa a ordem da matriz e $\lambda_{\operatorname{máx}}$ o estimador de autovalor máximo de julgamentos paritários.

Com objetivo de permitir a avaliação da inconsistência em função da ordem máxima da matriz de julgamento, Saaty e Vargas (2001) fazem uso da Razão de Consistência (RC) conforme Equação 2.

$$
R C=I C / I R
$$

Onde IR é um índice randômico de consistência obtido para uma matriz recíproca, com elementos não negativos gerados de forma randômica. Caso RC não atinja os limites estabelecidos, existe alguma inconsistência nos julgamentos e o especialista deve ser solicitado a rever a sua opinião. Os julgamentos da matriz de decisão são considerados consistentes se: $\mathrm{RC}=0$ para $\mathrm{n}=2, \mathrm{RC}<0,05$ para $\mathrm{n}=3, \mathrm{RC}<0,09$ para $\mathrm{n}=4$ e $\mathrm{RC} \leq 0,10$ para $\mathrm{n}>4$ (ALVES; ALVES, 2014, p.17). A Tabela 1 ilustra os resultados para IR em função da ordem da matriz utilizada. 
Proposta de alteração do layout de um centro de distribuição de produtos alimentícios utilizando simulação de cenários e o método de processo de análise hierárquica (AHP)

Tabela 1 - Índice Randômico Médio do AHP em função do tamanho da matriz.

\begin{tabular}{ccccccccccc}
\hline $\mathrm{N}$ & 2 & 3 & 4 & 5 & 6 & 7 & 8 & 9 & 10 & 11 \\
\hline $\mathrm{IA}$ & 0 & 0,58 & 0,9 & 1,12 & 1,24 & 1,32 & 1,41 & 1,45 & 1,49 & 1,51 \\
\hline
\end{tabular}

Fonte: Saaty (1980).

O autovalor $\lambda_{\text {máx }}$ é estimado a partir da Equação 3 (ARUEIRA, 2014).

$$
A w=\lambda_{\text {máx }} w
$$

Onde $A$ é a matriz $n \times n$, para $n$ critérios, também chamada de matriz de prioridade, e $w$ é o autovetor de tamanho $\mathrm{n} \times 1$, também chamado de vetor de prioridade.

O autovetor $w$ pode ser obtido ao se executar os seguintes passos (OLIVEIRA, BELDERRAIN, 2008):

a) Realizar a normalização dos elementos da coluna pelo quociente entre o elemento a ser normalizado e a soma dos elementos de cada coluna (Equação 4).

$$
A=a_{i j} / \sum_{i=1}^{m} a_{i j} \quad j=1, \ldots, n
$$

b) Fazer o somatório dos elementos de cada linha normalizada dividido pela ordem da matriz A (Equação 5).

$$
w\left(A_{i}\right)=\sum_{j=1}^{m} \frac{w\left(A_{j}\right)}{n} \quad \forall i=1, \ldots, n
$$

Após a obtenção do autovetor $w$ é possível calcular o autovalor $\lambda_{\text {máx }}$ associado através da Equação 3 apresentada de forma distinta na Equação 6 (OLIVEIRA, BELDERRAIN, 2008).

$$
\lambda_{\text {máx }}=\frac{1}{n} \sum_{i=1}^{n} \frac{[A w]_{i}}{w_{i}}
$$

Em função dos dados obtidos nas etapas anteriores, é possível determinar a importância de cada critério a partir da elaboração de um ranking das alternativas avaliadas (FREITAS; MARINS; SOUZA, 2006).

A pontuação de cada uma das alternativas provém do somatório do autovetor $w_{i}$ multiplicado pelo seu peso $_{i}$ (os pesos relativos de cada critério são determinados pelos gestores, e a soma dos pesos para todos os critérios deve ser igual a 1). 
Proposta de alteração do layout de um centro de distribuição de produtos alimentícios utilizando simulação de cenários e o método de processo de análise hierárquica (AHP)

\section{PROCEDIMENTOS METODOLÓGICOS}

O artigo desenvolvido é de natureza de pesquisa aplicada, segundo Gerhardt (2012) a pesquisa aplicada objetiva gerar conhecimentos para aplicação prática, dirigidos à solução de problemas específicos. A pesquisa é realizada neste trabalho de acordo com as etapas apresentadas na Figura 5. Basicamente, a etapa 1 é relativa aos procedimentos de coleta de dados e teve como objetivo entender o problema proposto; as etapas 2 e 3 estão relacionadas à análise de dados e elaboração da solução, utilizando conhecimento teórico para propor uma solução.

A etapa 1, pesquisa em campo, foi realizada durante os meses de abril a junho de 2018. Realizaram-se visitas ao Centro de Distribuição da empresa em estudo e levantaram-se os seguintes dados relacionados ao item 1.1 da Figura 5:

Figura 5 - Etapas realizadas no presente estudo.

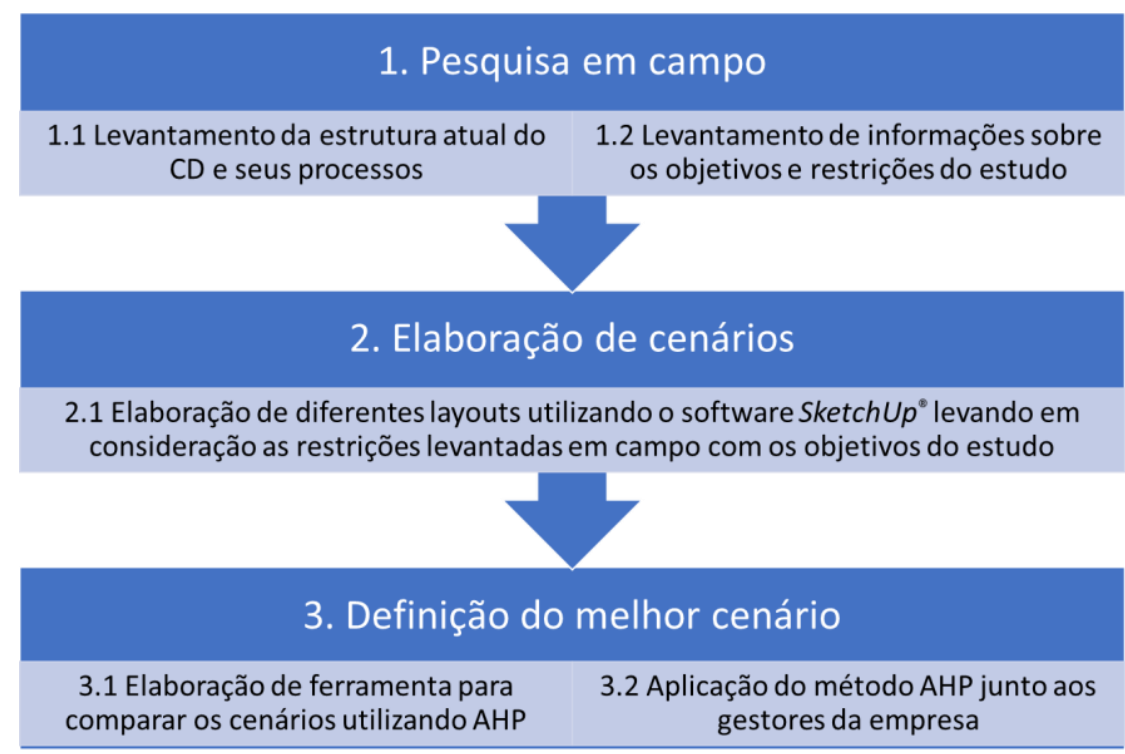

Fonte: Autores (2020).

a) Análise da estrutura física do Centro de Distribuição: verificou-se primeiramente quais as zonas existentes no $\mathrm{CD}$; departamentos administrativos, banheiros e áreas de escritório. Além disso, levantou-se o número de entradas, saídas, tipos de porta-pallets e número de posições pallet existentes. 
Proposta de alteração do layout de um centro de distribuição de produtos alimentícios utilizando simulação de cenários e o método de processo de análise hierárquica (AHP)

b) Análise de equipamentos: analisaram-se quais equipamentos de movimentação são utilizados no CD. A análise de equipamentos é crucial para o desenvolvimento do layout pois é ela que determina a largura dos corredores que serão projetados.

c) Levantamento do fluxo de produtos: levantaram-se todas as operações realizadas no $\mathrm{CD}$ em estudo, com principal foco no fluxo operacional do produto, ou seja, a sequência lógica que o material se movimenta pelo $\mathrm{CD}$, desde sua entrada até sua saída.

Todas as informações obtidas da pesquisa em campo estão descritas na seção 3.1. Já o levantamento das informações referentes à etapa 1.2 da Figura 5 deu-se através de uma reunião realizada com os gestores da empresa ainda em abril de 2018 (ver seção 3.2). Nesta reunião foram repassadas informações como a capacidade mínima necessária para atender a demanda prevista em 2019, as estruturas de armazenagem possíveis de serem alocadas ao CD, objetivo do projeto.

A partir dos dados fornecidos a etapa 2, da Figura 5, foi realizada. Elaborou-se no software SketchUp ${ }^{\circledR}$ a configuração física e detalhada do CD original. A partir da situação atual são propostos (utilizando o mesmo software) cenários com diferentes layouts que atendam às necessidades operacionais da empresa.

A definição do melhor cenário (etapa 3) analisa as propostas de layout elaboradas em cada cenário utilizando o Método de Análise Hierárquica (AHP). Para utilização do AHP na escolha do melhor cenário elaborou-se uma planilha eletrônica no software Excel $^{\circledR}$ (etapa 3.1) com todas as matrizes e cálculos do método AHP apresentados na seção 2.3. A aplicação da ferramenta (etapa 3.2) foi realizada com o gestor da empresa em uma reunião física na empresa. Após a compilação dos dados fornecidos obteve-se o cenário de maior pontuação com o layout a ser sugerido para implantação no CD.

\subsection{Objeto de estudo - Caracterização do centro de distribuição e suas operações}

A empresa deste estudo de caso é uma das empresas líderes mundiais no setor de alimentos e bebidas. Possui interesse na fabricação, comercialização e distribuição de lanches à base de grãos, bebidas e outros produtos. Sua operação em território nacional engloba 15 plantas de produção e mais de 100 filiais de vendas e centros de distribuição.

Este projeto foi desenvolvido em um dos Centros de Distribuição da empresa, localizado na cidade de Araquari - SC. 
Proposta de alteração do layout de um centro de distribuição de produtos alimentícios utilizando simulação de cenários e o método de processo de análise hierárquica (AHP)

O centro de distribuição deste estudo possui $4320 \mathrm{~m}^{2}$ e é subdividido em zonas, definidas de acordo com as operações realizadas (Figura 6). Por critério da empresa as zonas devem ser mantidas de acordo com o layout atual, sendo necessário o desenvolvimento do novo layout apenas para a zona de armazenagem (área destacada na Figura 6). A seguir temse a descrição de cada uma das zonas do Centro de Distribuição da Figura 6.

- Zonas de Carga e Descarga: O Centro de Distribuição possui 16 docas para as operações de carga e descarga de veículos. Em frente a cada uma das docas reserva-se uma área de $40 \mathrm{~m}^{2}$ para a separação e movimentação de produtos durante esta operação.

- Zona de armazenagem: A zona de armazenamento atual é constituída de box's demarcados no piso do Centro de Distribuição, possui corredores de 3,5 metros, tamanho definido para passagem e manobra do equipamento de movimentação utilizado, que é a empilhadeira a combustão. A estrutura de armazenamento atualmente utilizada são pallets blocados, sendo que a armazenagem blocada consiste em armazenar pallets de produtos uns sobre os outros no chão de um armazém (JERMSITTIPARSERT; SUTDUEAN; SRIYAKUL, 2019). Devido a fragilidade da carga que não permite o empilhamento de pallets, o armazenamento é realizado em somente um nível. Todos os produtos são armazenados em caixas e não é necessário nenhum tipo de controle de temperatura. Todos os corredores possuem duplo sentido de circulação, de acordo com a recomendação da segurança de trabalho da empresa.

- Zonas de apoio: O CD possui $248 \mathrm{~m}^{2}$ de área de escritório de apoio as atividades logísticas e uma área de $232 \mathrm{~m}^{2}$ para a guarda de insumos e de equipamentos de movimentação ao final do expediente. A área de banheiro e copa localizam-se fora da delimitação do CD. 
Proposta de alteração do layout de um centro de distribuição de produtos alimentícios utilizando simulação de cenários e o método de processo de análise hierárquica (AHP)

Figura 6 -: Layout do Centro de Distribuição atual com a divisão da área por zonas.

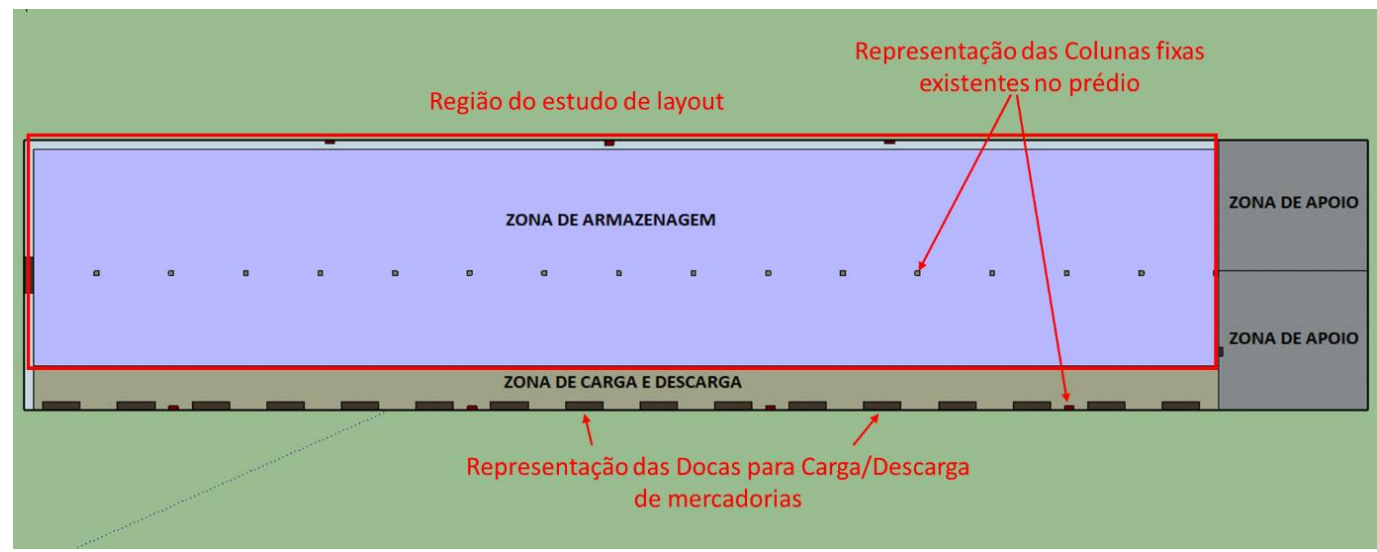

Fonte: Autores (2020).

As seguintes operações são realizadas atualmente no Centro de Distribuição:

- Descarga: Todos os produtos são recebidos no Centro de Distribuição através de veículos com carga batida (com aproximadamente 2000 caixas por veículo). A operação de descarga contempla a conferência da mercadoria no mesmo momento em que ela é paletizada. A paletização é realizada por auxiliares de movimentação, que realizam esta atividade no interior do veículo, após sua finalização há a colagem da etiqueta e o deslocamento da empilhadeira para retirada do pallet do caminhão em direção à zona de armazenagem.

- Separação: Nenhuma carga é fracionada, ou seja, não é necessário a abertura de nenhuma caixa para a retirada de produtos. Todas as mercadorias são expedidas em pallets fechados, sem necessidade de nenhum manuseio de produtos dentro do pallet. A separação é realizada antes do veículo chegar na empresa, os pallets separados são alocados na doca que irá atender aquele determinado veículo.

- Carga: As mercadorias são expedidas de forma paletizada, a atividade de carregamento contempla a conferência e a etiquetagem dos pallets com as informações do cliente.

- Armazenagem: Os veículos chegam no Centro de Distribuição carregados com um único tipo de produto (que possui diferentes SKU's), de acordo com sua cor, sabor e tamanho. A paletização também ocorre desta maneira, cada pallet contém apenas um tipo de produto com SKU's diferentes, de modo que os produtos sejam armazenados da maneira que serão expedidos. 
Proposta de alteração do layout de um centro de distribuição de produtos alimentícios utilizando simulação de cenários e o método de processo de análise hierárquica (AHP)

\subsection{Objeto de estudo - Objetivo do estudo}

$\mathrm{Na}$ reunião realizada com os gestores sobre o escopo do trabalho definiu-se que o principal objetivo é realizar a ampliação da capacidade do armazém atual que já está construído e em operação. Os pallets utilizados no armazém e que serão considerados para o desenvolvimento dos layouts são os pallets PBR (Pallet Padrão Brasileiro), de medidas 1,00x1,200m. O número de pallets e SKUs (Stock Keeping Units) armazenados nos primeiros quatro meses de 2018 estão descritos na Tabela 2.

Tabela 2 - Volumes de pallets armazenados no Centro de Distribuição.

\begin{tabular}{lccc}
\hline \multicolumn{1}{c}{ MÊS } & MÉDIA DE PALLETS & PICO DE PALLETS & MÉDIA DE SKU \\
\hline JANEIRO & & & \\
\hline FEVEREIRO & 987 & 1132 & 87 \\
\hline MARÇO & 980 & 1140 & 107 \\
\hline ABRIL & 1049 & 1253 & 11 \\
\hline MÉDIA & 1002 & 1162 & 83 \\
\hline Previsão 2019 & 1005 & 1172 & 127 \\
\hline
\end{tabular}

Fonte: Empresa estudada (2018).

A empresa estima um aumento de $22 \%$ no número de pallets armazenados para o ano de 2019 , isto reflete em uma média de 1225 pallets na maior parte do mês e 1430 pallets em períodos de pico. Porém, considerando o histórico de crescimento anual da empresa espera-se que o novo layout do Centro de Distribuição ultrapasse essa necessidade estimada e que deixe a empresa preparada para as futuras variações a longo prazo, para que possa executar suas operações com eficiência independente de sua demanda.

\subsection{Objeto de estudo - Definição dos critérios para elaboração das alternativas de layout}

Como torna-se inviável simular todas as alternativas possíveis de layout, na mesma reunião em que se definiu os objetivos do estudo verificou-se com os gestores da empresa quais seriam os critérios a serem considerados na avaliação/escolha do novo layout. Assim, foram definidos três critérios como de suma importância para a avaliação do novo layout, sendo eles: (i) o aumento da capacidade do futuro layout, (ii) a segurança nas movimentações internas e, por último, (iii) a eficiência de cada proposta de layout.

A escolha do critério capacidade está diretamente relacionada ao número de posições pallet que cada proposta de layout irá armazenar. Levando em consideração que o layout atual 
Proposta de alteração do layout de um centro de distribuição de produtos alimentícios utilizando simulação de cenários e o método de processo de análise hierárquica (AHP)

da empresa não possui a verticalização das suas posições pallets, definiu-se que todas as propostas apresentariam essa solução, ocasionando em todas as alternativas um aumento de posições em relação ao encontrado hoje. Para análise de capacidade levou-se em consideração todas as posições pallets possíveis de alocação no $\mathrm{CD}$, reduzindo-se todas as posições que possuíam impossibilidade de acesso devido as colunas fixas da estrutura. Além disso, descontou-se também as posições que inibiam o acesso aos extintores de incêndio da planta.

Outro critério considerado foi a segurança na movimentação de carga de cada layout. Este critério foi considerado importante, devido à existência de obstáculos na zona de armazenagem do Centro de Distribuição (colunas fixas no prédio, ver Figura 6). Os obstáculos presentes nas vias podem ocasionar acidentes de trabalho, colocando em risco o operador, equipamento e carga.

O terceiro critério considerado foi a eficiência de cada layout apresentado. Neste parâmetro leva-se em consideração as facilidades da movimentação e acesso a determinados pontos do Centro de Distribuição, e as distâncias percorridas pelo fluxo dos produtos.

Estes três critérios serão também utilizados no processo de ranqueamento dos modelos de layout desenvolvidos utilizando o método de análise Analytic Hierarchy Process (AHP).

Além dos três critérios apresentados, todos os layouts desenvolvidos neste estudo levaram em consideração os cinco princípios do desenvolvimento de layout descritos por Peinaldo e Graeml (2007).

Com base no princípio de Segurança, elaboraram-se layouts seguindo a planta de incêndio do armazém e desconsiderando as posições pallets que inibiam o acesso aos corredores, pois na fase de implantação do projeto estas posições serão removidas.

O segundo princípio refere-se a economia de movimento, a fim de evitar caminhos aleatórios definiu-se um comprimento máximo de 30m para cada porta pallet, de modo que o operador não precise percorrer grandes distâncias para ter acesso as docas do CD.

O terceiro princípio diz respeito a flexibilidade a longo prazo, neste estudo de layout a flexibilidade é resultado do tipo de porta pallet que será utilizado, a preferência será dada a um modelo que permita adaptações no tamanho de suas posições pallet e ajustes na altura de seus níveis.

O quarto princípio refere-se a progressividade, que consistiu em definir um fluxo para o produto, planejando sua entrada, sua forma de movimentar-se pelo Centro de Distribuição e sua saída. 
Proposta de alteração do layout de um centro de distribuição de produtos alimentícios utilizando simulação de cenários e o método de processo de análise hierárquica (AHP)

Já o quinto princípio descreve o uso de espaço, todos os layouts desenvolvidos consideraram corredores de movimentação com largura padrão, que é a necessária para passagem e manobra da empilhadeira, sendo de 3,5 metros. Além disso, todos os modelos levaram em consideração a estrutura de armazenagem verticalizada e respeitaram as zonas delimitadas no Centro de Distribuição.

O critério custo não foi levado em consideração, uma vez que o custo deste investimento não teria influência nenhuma sobre a qualidade diária da operação logística. Além disto, o custo de investir em porta pallets não depende da configuração do layout, e sim exclusivamente da quantidade de posições pallets necessárias. Por essas razões o custo relativo ao layout é analisado pela empresa somente após ter um modelo escolhido e cotado pelos diferentes fornecedores do serviço, desta forma, não se tratará de uma análise entre layouts e sim de uma análise entre fornecedores.

\section{RESULTADOS E DISCUSSÕES}

\subsection{Simulação de cenários desenvolvidas}

Com o principal objetivo de aumentar a capacidade de armazenagem da empresa, optou-se pela verticalização do armazém. Nos layouts desenvolvidos foi considerada a atual demarcação para as zonas de carga, descarga e de escritório, e um novo padrão de demarcação para as áreas de movimentação, sendo:

- Corredor de movimentação com largura de 3,5m;

- Corredor de passagem com largura de $1 \mathrm{~m}$.

Verifica-se, pela revisão de literatura apresentada, a possibilidade de formular layouts no estilo tradicional (Figura 1), em formato Y (Figura 2) ou de espinha de peixe (Figura 3).

Entretanto, a utilização dos layouts não tradicionais (Figura 2 e 3) foi logo descartada por alguns motivos:

- Limitações físicas de espaço: Ao se analisar a implantação de todos os modelos de layouts levou-se em consideração, em primeiro lugar, as limitações físicas do armazém. Na planta apresentada na Figura 6 é possível observar que o Centro de Distribuição é dividido por um eixo horizontal de 15 colunas, o que dificulta a implantação de layouts não tradicionais, em razão da diferença de angulação que as fileiras de porta pallets e corredores de circulação teriam que possuir para se adequar a estrutura. 
Proposta de alteração do layout de um centro de distribuição de produtos alimentícios utilizando simulação de cenários e o método de processo de análise hierárquica (AHP)

- Análise do projeto de combate a incêndio: Uma questão crucial a ser levada em consideração na análise do layout do armazém é sua planta de combate a incêndio do local de estudo. Segundo a Associação Brasileira de Normas Técnicas (ABNT), por meio da NBR 15.524-2/2008 (Sistema de Armazenagem) os materiais devem estar alocados de forma a não obstruir, de forma total ou parcial, portas, saídas de emergência ou ocultar equipamentos contra incêndios. Na primeira análise de escolha das possibilidades de layouts a serem estudadas, observou-se que a implantação dos layouts não tradicionais, em formato $\mathrm{Y}$ e espinha de peixe, estaria em desacordo com o projeto de combate a incêndio da empresa, e consequentemente, em desacordo com a norma citada da ABNT.

- Roteirização: A análise de escolha das possibilidades de layout a serem estudadas também considerou importante a determinação dos movimentos a serem feitos para separação dos pedidos. Neste quesito, pensando na facilidade de movimentação e na segurança dos colaboradores que fariam o percurso com a empilhadeira, buscaram-se layouts constituídos por ângulos retos, com poucas quebras e pontos de cruzamento, a fim de tornar o percurso o mais contínuo possível em relação a doca e reduzir a existência de pontos cegos na movimentação de empilhadeira, tornando o percurso eficiente e seguro.

Assim, elaboraram-se diversas alternativas de layout (cenários) usando como base o estilo tradicional. Todas as propostas possuem 3 níveis de verticalização, que é a altura máxima permitida pela estrutura física do Centro de Distribuição. Todas as alternativas de layout foram desenvolvidas via software SketchUp ${ }^{\circledR}$, que permite elaborar modelos 3D de instalações de armazéns com alto nível de detalhe.

As opções de layouts que não se atenderam aos critérios de segurança (projeto de combate a incêndio e as normas técnicas de armazenagem definidas pela ABNT) foram eliminados da análise. Assim, serão apresentados, nas próximas seções, os três modelos de layout que atendem os critérios de segurança e resultaram nas mais altas capacidade de armazenagem, uma vez que este é o principal objetivo da alteração de layout. Cada uma das três alternativas apresenta diversas vantagens e desvantagens, que serão analisados pelos gestores utilizando o método AHP para concluir qual deve ser escolhida. 
Proposta de alteração do layout de um centro de distribuição de produtos alimentícios utilizando simulação de cenários e o método de processo de análise hierárquica (AHP)

\subsubsection{Cenário 1 - somente corredores verticais}

A primeira alternativa elaborada, layout 1 (Figura 7), possui um fácil acesso as docas, sendo que todos os corredores dão acesso a uma doca. Para a equipe de picking facilita a separação de produtos, além de possui um padrão de movimentação intuitivo.

A principal desvantagem é que algumas colunas estão no meio dos corredores principais ou anexas aos porta pallets, sendo necessário dividir cada estrutura em duas partes, o que possivelmente acarretará um maior custo de investimento.

Figura 7 - Proposta do Layout 1 - somente corredores verticais.

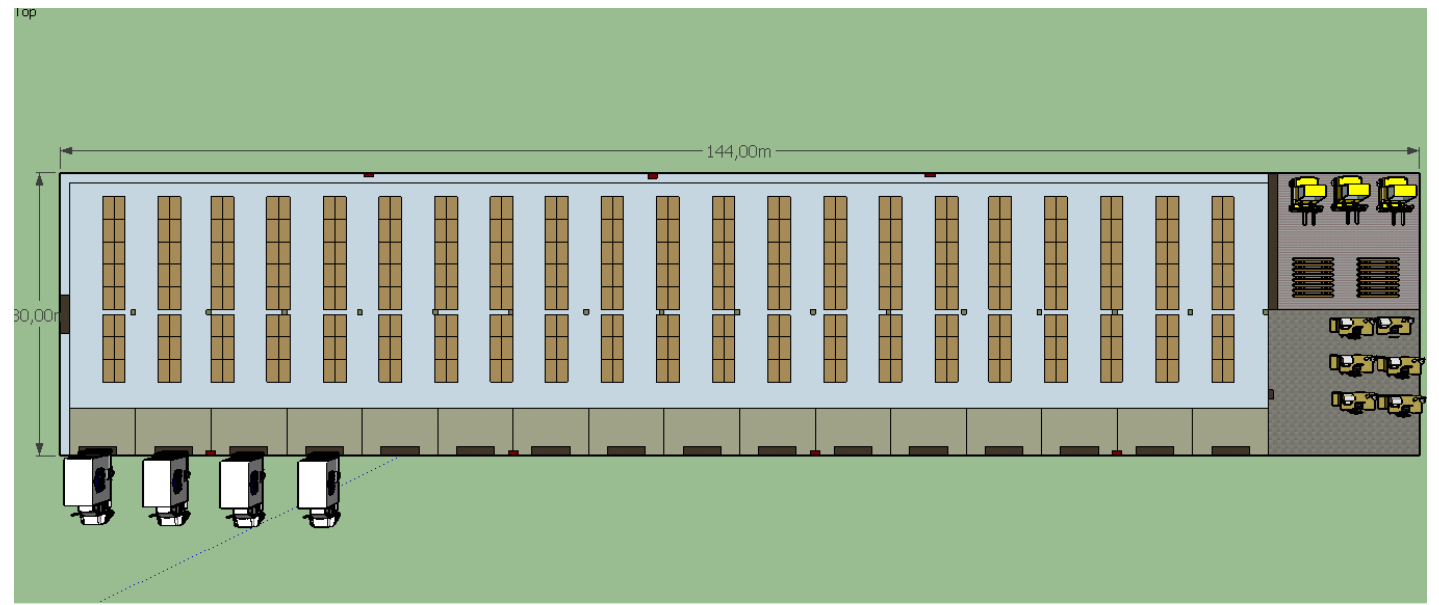

Fonte: Autores (2020).

Este modelo possui capacidade de 2016 posições pallet. Levando em consideração a necessidade da empresa para 2019 de 1430 pallets no pico (Tabela 1), esta é uma ótima alternativa considerando a impossibilidade de adquirir novos espaços físicos.

\subsubsection{Cenário 2 - somente corredores horizontais}

A grande vantagem do layout 2 (Figura 8) é o padrão de movimentação intuitivo, ele possui quatro corredores que permitem o percurso do Centro de Distribuição do início ao fim de forma contínua. 
Proposta de alteração do layout de um centro de distribuição de produtos alimentícios utilizando simulação de cenários e o método de processo de análise hierárquica (AHP)

Figura 8 - Proposta do Layout 2 - somente corredores horizontais.

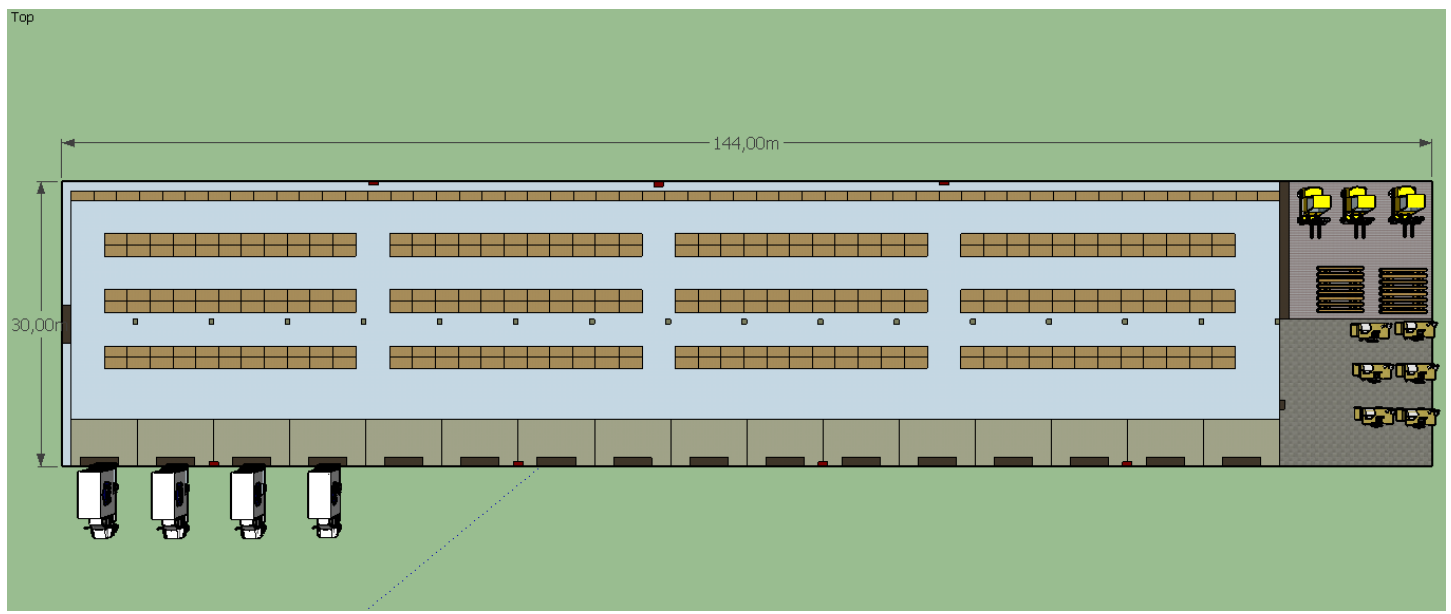

Fonte: Autores (2020).

No processo de separação de produto, caso o operador escolha por percorrer e separar os produtos de forma fracionada, ou seja, percorrer diversas partes do armazém para formar um pedido, seria mais relevante este layout.

A grande desvantagem deste modelo é a área inutilizada localizada em frente a zona de carga e descarga, por não ser possível a alocação de mais um porta pallet. Além disso, o acesso as docas exigem maior movimentação quando comparado ao layout 1.

É observado um corredor inteiro com a movimentação comprometida pela existência de obstáculos fixos (colunas). Este modelo tem capacidade de 1824 posições pallet. Mesmo menor que o cenário 1, este layout supre a necessidade de capacidade para 2019.

\subsubsection{Cenário 3 - mescla de corredores verticais e horizontais}

O último modelo tradicional de maior capacidade desenvolvido (Layout 3, Figura 9) possui baixo número de obstáculos nos corredores (somente 2 com colunas no meio do corredor), o que facilita a circulação e reduz o risco de acidentes.

Outra vantagem é que o centro de distribuição do modelo permite uma subdivisão simplificada das estruturas de armazenagem de acordo com o tipo de produto, (sendo a primeira metade destinada aos alimentos e a segunda metade para bebidas, por exemplo), o que facilita o processo de picking.

A desvantagem é o padrão de movimentação não intuitivo, em razão da diferença na direção dos porta pallets. Este modelo possui uma capacidade intermediaria de 1902 posições pallet. 
Proposta de alteração do layout de um centro de distribuição de produtos alimentícios utilizando simulação de cenários e o método de processo de análise hierárquica (AHP)

Figura 9 - Proposta do Layout 3 - mescla de corredores verticais e horizontais.

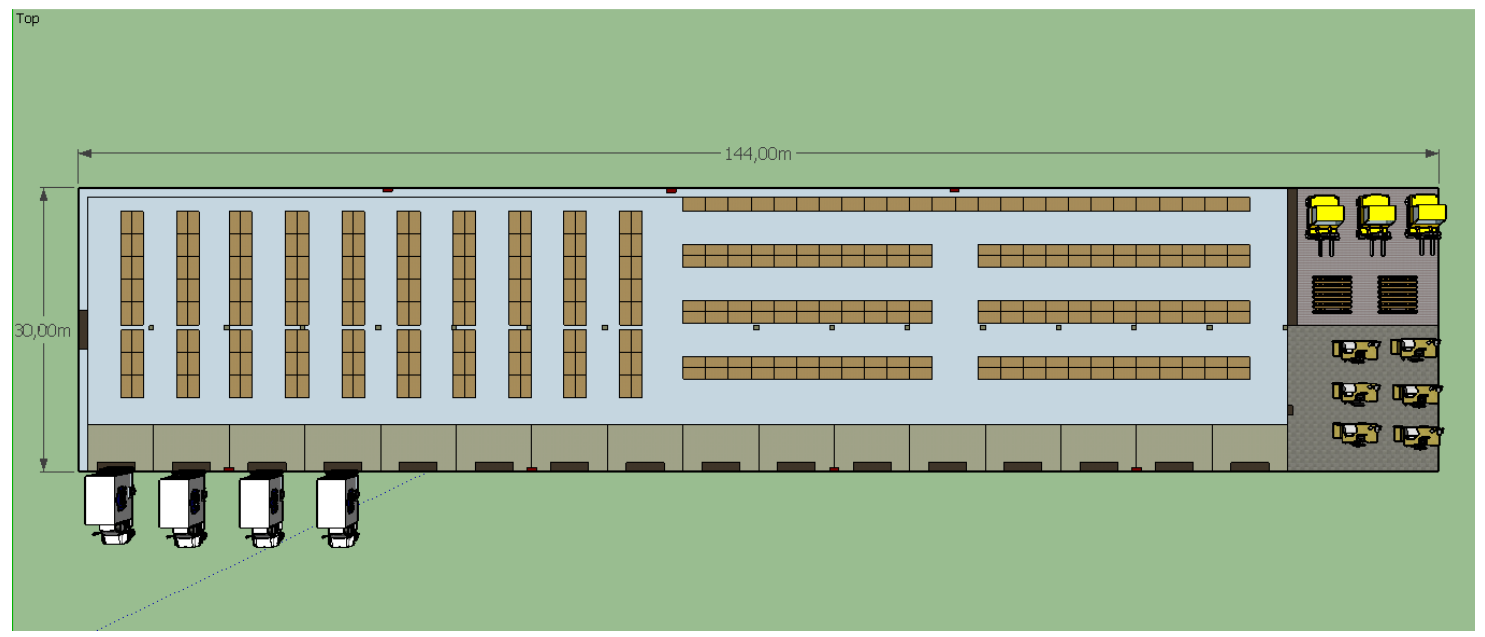

Fonte: Autores (2020).

\subsection{Aplicação do AHP para avaliação dos cenários}

Para a utilização do método AHP, foi inicialmente elaborada uma estrutura hierárquica contendo os três níveis necessários para a tomada de decisão (Figura 10). No primeiro nível temos o objetivo principal da análise multicritério, que é definir o melhor layout para a empresa do estudo de caso; no segundo nível encontram-se os critérios que serão utilizados pelos gestores para a tomada de decisão; e no terceiro nível estão as propostas de layout (cenários) que foram apresentadas para a empresa.

Figura 10 - Estrutura hierárquica utilizada na aplicação do AHP.

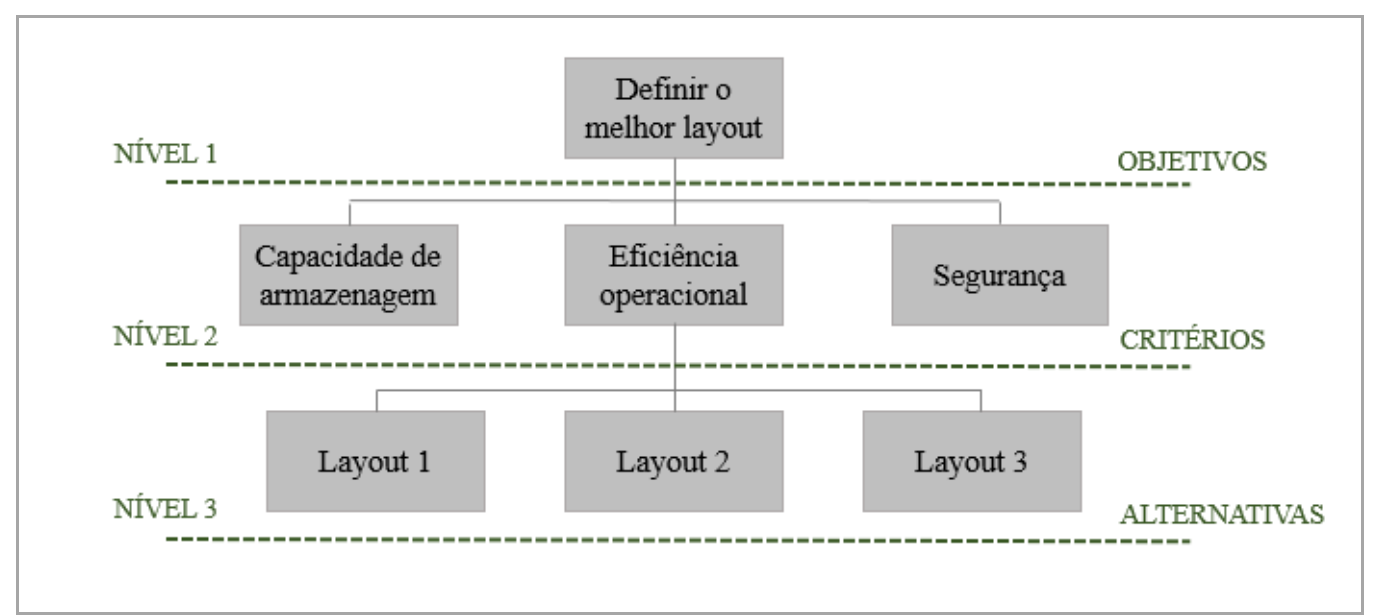

Fonte: Autores (2020). 
Proposta de alteração do layout de um centro de distribuição de produtos alimentícios utilizando simulação de cenários e o método de processo de análise hierárquica (AHP)

Para que a ferramenta de cálculo dos indicadores AHP pudesse ser elaborada era necessário definir os pesos de cada um dos três critérios avaliados. A Tabela 3 demonstra os pesos definidos pelo principal gestor do CD.

Tabela 3 - Pesos dos critérios.

\begin{tabular}{c|c|c|c}
\hline & $\begin{array}{c}\text { Capacidade de } \\
\text { Armazenagem }\end{array}$ & $\begin{array}{c}\text { Eficiência } \\
\text { Operacional }\end{array}$ & Segurança \\
\hline $\begin{array}{c}\text { Grau de importância de } \\
\text { cada critério }\end{array}$ & 0,5 & 0,3 & 0,2 \\
\hline
\end{tabular}

Fonte: Gestor da empresa estudada (2018).

A definição dos pesos para cada um dos critérios levou em consideração os seguintes pontos acerca de cada critério:

- Capacidade de Armazenagem: A decisão pela alteração do layout do Centro de Distribuição foi tomada em razão da necessidade de aumentar a capacidade do Centro de Distribuição, causada pelo aumento previsto de vendas, e consequentemente da necessidade de espaço. Sem o aumento da capacidade de armazenagem, a empresa seria incapaz de atender toda a demanda prevista para unidade, desta forma, não haveria motivo que justificasse o desenvolvimento do projeto. Por esta razão, para este critério foi atribuído o maior peso, e que corresponde a 50\% da decisão, e será medido pela quantidade de posições pallets que o Centro de Distribuição é capaz de armazenar. Para o gestor, é interessante, adquirir a maior capacidade possível de armazenagem, a fim de manter o Centro de Distribuição preparado, em sua melhor configuração, para quaisquer novas previsões de aumento de vendas que venham a ocorrer nos anos posteriores a 2019.

- Eficiência: Na alteração do layout do Centro de Distribuição, é necessário pensar na funcionalidade de realizar a separação dos pedidos. Indicadores como Tempo de atendimento ao pedido e Pedidos entregues no prazo são controlados diariamente pela empresa, pois tem influência direta no atendimento ao cliente e na imagem que a empresa projeta no mercado. Atualmente a empresa trabalha com indicadores envolvendo metas já definidas e que precisam ser mantidas. Desta forma, para este critério foi estabelecido o peso de $30 \%$, e será medido pela facilidade de percurso das rotas de picking.

- Segurança: Como nesta análise estão somente modelos de layout que atendem aos critérios mínimos de segurança estabelecidos, este critério, definido pelo gestor, tem o 
Proposta de alteração do layout de um centro de distribuição de produtos alimentícios utilizando simulação de cenários e o método de processo de análise hierárquica (AHP)

objetivo de analisar os percursos percorridos com a menor existência de obstáculos e pontos de cruzamentos possíveis pelas empilhadeiras, ou seja, pela menor chance de colisões e acidentes. É definido com peso de $20 \%$ da decisão, pela possibilidade de criação de normas de segurança, sinalizações internas e treinamento aos colaboradores que buscassem tornar as operações de movimentação mais seguras.

Para aplicar a metodologia criada por Saaty (1980) e hierarquizar as alternativas é necessário formar matrizes de comparação pareadas, onde nestas são relacionados os critérios considerados para a definição do melhor layout. Cada item deve ser avaliado em importância utilizando a escala fundamental de Saaty de 1 a 9.

A ferramenta elaborada para aplicação do método AHP foi uma planilha eletrônica que realizou os respectivos cálculos conforme apresentados na revisão bibliográfica sobre o assunto. A Figura 11 demonstra uma das abas da planilha com as respectivas fórmulas em cada uma das células, apresentadas na seção 2.3. A matriz A normalizada (células A9 até D13) é calculada de acordo com a equação 4, o índice de coerência (equação 1) está na célula B21, a razão de consistência (equação 2) na célula B25 e o resultado das equações 3,5 e 6 está na célula B18.

Em cada aba da planilha é realizada a comparação entre os layouts 1, 2 e 3 para um critério (na Figura 11 está selecionada a aba Capacidade Armazenagem).

As únicas células que são preenchidas pelo gestor da empresa são C2, D2 e D3, em cada aba, visto que a parte inversa da matriz já é calculada automaticamente. 
Proposta de alteração do layout de um centro de distribuição de produtos alimentícios utilizando simulação de cenários e o método de processo de análise hierárquica (AHP)

Figura 11 - Planilha eletrônica elaborada para aplicação do AHP (já preenchida na Matriz A).

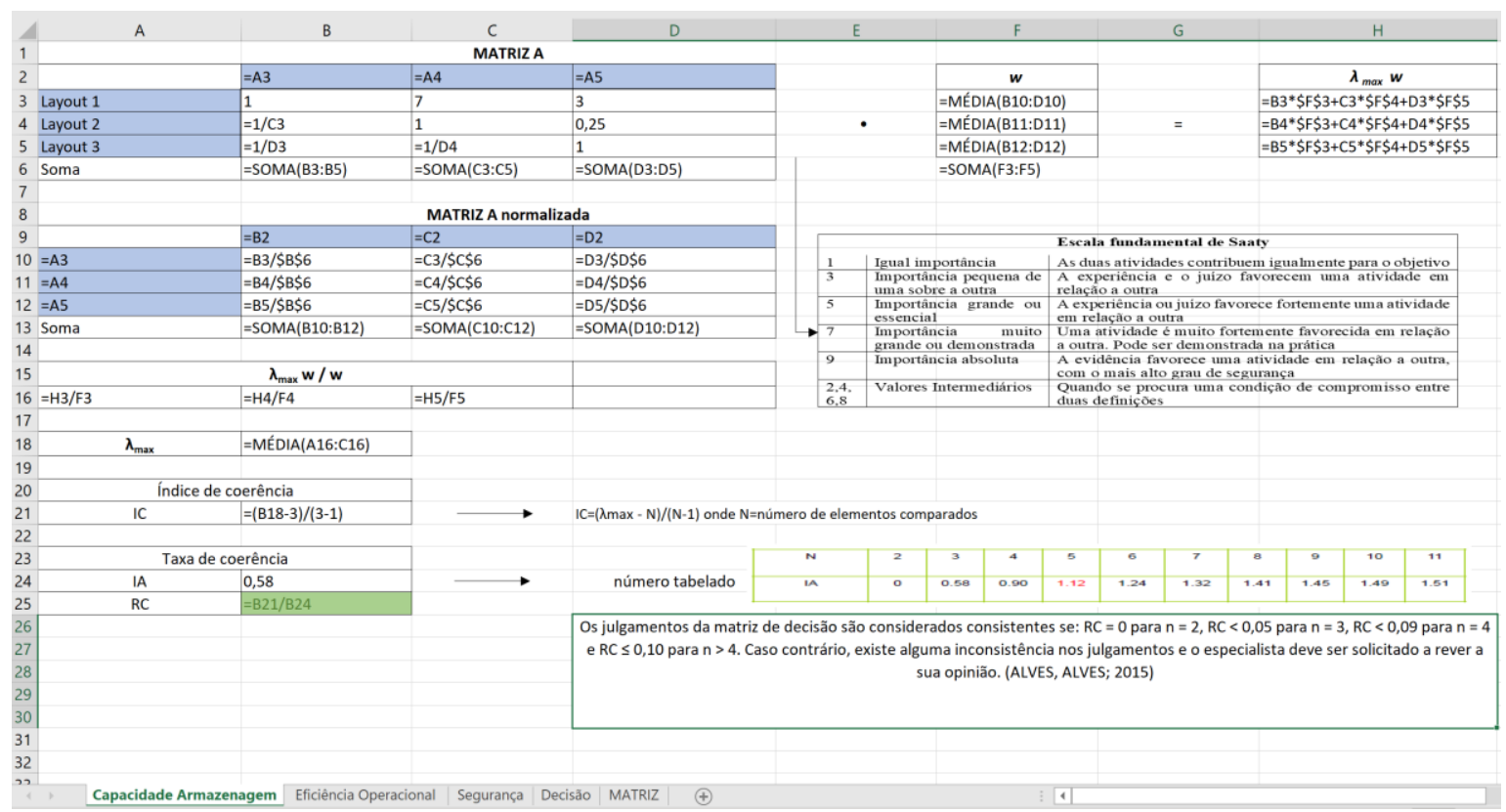

Fonte: Autores (2020).

A comparação entre os layouts foi realizada pelos gestores da empresa, que atribuíram os valores na matriz para realizar as comparações. Vale destacar que para o critério Eficiência os gestores realizaram, de forma intuitiva, uma análise da facilidade de chegar nas docas (ponto final) a partir de rotas de picking no início, meio e fim do armazém (pontos de partida), considerando para cada uma a existência de obstáculos, número de curvas, continuidade dos corredores. Assim, as matrizes de comparação para os critérios capacidade (Tabela 4), segurança (Tabela 5) e eficiência (Tabela 6) são discutidas a seguir.

Tabela 4 - Comparação entre os níveis 2 e 3 - Critério Capacidade

\begin{tabular}{llll}
\hline CAPACIDADE & Cenário 1 & Cenário 2 & Cenário 3 \\
\hline Cenário 1 & 1,000 & 7,000 & 3,000 \\
\hline Cenário 2 & 0,143 & 1,000 & 0,250 \\
\hline Cenário 3 & 0,333 & 4,000 & 1,000
\end{tabular}

Fonte: Autores (2020).

O critério Capacidade, que possui o maior peso entre os critérios, avaliou a quantidade de posições pallets de cada modelo, sendo o layout 1 com 2016 posições pallets, o layout 2 com 1824 posições pallets e o layout 3 com 1900 posições pallets. Sendo desta forma, o layout 1 terá a maior pontuação. 
Proposta de alteração do layout de um centro de distribuição de produtos alimentícios utilizando simulação de cenários e o método de processo de análise hierárquica (AHP)

Tabela 5 - Comparação entre os níveis 2 e 3 - Critério Segurança

\begin{tabular}{cccc}
\hline SEGURANÇA & Cenário 1 & Cenário 2 & Cenário 3 \\
\hline Cenário 1 & 1,000 & 3,000 & 0,333 \\
\hline Cenário 2 & 0,333 & 1,000 & 0,200 \\
\hline Cenário 3 & 3,000 & 5,000 & 1,000
\end{tabular}

Fonte: Autores (2020).

Ao analisar a Segurança do Centro de Distribuição, leva-se em consideração a existência de obstáculos das rotas de picking, o que eventualmente poderia causar colisões e acidentes. O obstáculo mais crítico da área de armazenagem são as colunas estruturais. É importante ressaltar, que colunas próximas ou anexas ao porta pallet, não apresentam um risco relevante na movimentação da empilhadeira, por não necessitar de grandes desvios ou manobras. Assim, levou-se em consideração apenas as colunas que sejam de fato, um obstáculo na passagem das empilhadeiras. Desta forma, o layout 3 é o que recebe maior pontuação por ter menor número de colunas nos corredores de passagem.

Tabela 6 - Comparação entre os níveis 2 e 3 - Eficiência

\begin{tabular}{cccc}
\hline EFICIÊNCIA & Cenário 1 & Cenário 2 & Cenário 3 \\
\hline Cenário 1 & 1,000 & 3,000 & 5,000 \\
\hline Cenário 2 & 0,333 & 1,000 & 3,000 \\
\hline Cenário 3 & 0,200 & 0,333 & 1,000
\end{tabular}

Fonte: Autores (2020).

O critério eficiência está relacionado com as melhores práticas com que a operação de separação pode ser efetuada. A otimização da roteirização do armazém é fator determinante no tempo de separação dos pedidos, e o layout 1 recebe a maior pontuação por possuir todos os corredores de armazenagem direcionados a área de carga e descarga, o que torna a operação de movimentação mais rápida e ágil. Outro ponto importante a observar é a padronização de todas as estruturas de armazenagem, o que permite a padronização dos endereçamentos e da roteirização. As padronizações dos processos dentro de um armazém podem minimizar erros de separação, evitar prejuízos causados pela movimentação e reduzir o tempo de montagem dos pedidos, o que torna a operação mais eficiente e assertiva.

Todas as matrizes tiverem sua razão de consistência menores que 5\%, o que, segundo Alves e Alves (2014), valida a análise realizada pelos gestores. 
Proposta de alteração do layout de um centro de distribuição de produtos alimentícios utilizando simulação de cenários e o método de processo de análise hierárquica (AHP)

A partir da matriz de comparação pareada para os três cenários propostos, a Tabela 7 demonstra que o método sugere como resultado a escolha do layout do cenário 1 , ficando este com um peso de escolha de aproximadamente 56\% enquanto o layout cenário 2 obteve $13,63 \%$, e o cenário $329,99 \%$.

Tabela 7 - Resultado do método AHP.

\begin{tabular}{lc}
\hline Cenário 1 - layout somente corredores verticais & $\mathbf{5 6 , 3 8 \%}$ \\
\hline Cenário 2 - layout somente corredores horizontais & $13,63 \%$ \\
\hline Cenário 3 - layout com mescla de corredores verticais e horizontais & $29.99 \%$
\end{tabular}

Fonte: Autores (2020).

Visto que o maior peso estava para o critério capacidade (conforme Tabela 3) e a maior discrepância no comparativo entre os cenários foi relacionado a este critério (Tabela 4), o cenário 1 foi o escolhido por ser superior aos outros dois na capacidade de armazenagem. Vale ressaltar que apesar de não ser o melhor no quesito segurança (Tabela 5), o layout 1 atende os critérios mínimos estabelecidos pela empresa e também os apresentados por Gu et al. (2010) e Peinado e Graeml (2007) (ver seção 2.2). Portanto, o cenário 1 deve ser implementado no armazém da empresa.

\section{CONCLUSÕES}

Os armazéns têm um papel importante para que a empresa garanta alta competitividade no mercado, por isso deve-se buscar melhorar a movimentação dos materiais existentes nele, de maneira que se aproveite o máximo do espaço físico disponível, respeitando sempre as normas de segurança. Assim, um layout correto contribui com estes objetivos, aumentando a produtividade ao agilizar as operações e reduzir custos e tempo gastos nas operações.

Porém, devido as diversas especificidades físicas e mercadológicas de cada armazém, uma metodologia genérica para definição do layout dificilmente gera resultados satisfatórios ou aplicáveis na prática. Assim, esse trabalho apresenta a utilização de ferramentas existentes na literatura com softwares comerciais como alternativas para a definição do layout de um armazém.

Neste contexto, este estudo apresentou propostas para a alteração do layout do Centro de Distribuição de uma empresa multinacional do setor de alimentos e bebidas. Diversos cenários foram simulados considerando as restrições físicas do armazém e objetivos do 
Proposta de alteração do layout de um centro de distribuição de produtos alimentícios utilizando simulação de cenários e o método de processo de análise hierárquica (AHP)

projeto conflitantes, o que determinou a utilização de uma ferramenta multicritério de auxílio a decisão para definição do layout a ser implantado.

A revisão bibliográfica apresenta diversas configurações de layout de armazéns possíveis de serem simulados. Contudo, devido às restrições físicas do armazém e dificuldades na operação, somente layouts com estilo tradicional foram simulados utilizando o software SketchUp ${ }^{\circledR}$. Finalmente, os três cenários com layouts que apresentam as maiores capacidades de armazenagem são detalhados e apresentados aos gestores da empresa.

Para auxiliar na tomada de decisão do melhor cenário foi utilizada a metodologia de análise multicritério AHP, visto que o processo decisório envolvia muitas variáveis e os critérios abordavam dados quantitativos e qualitativos, sendo este um dos métodos mais recomendados.

Dessa forma foi possível encontrar a proposta de layout que melhor atende aos interesses da empresa. A definição do cenário 1 como melhor opção vai de acordo com a necessidade da empresa, visto que o aumento da capacidade foi o critério de maior peso entre os apresentados, dessa forma, este critério acabou sendo praticamente decisivo para este resultado. Finalmente, o método AHP se mostrou uma ótima opção neste caso, em que os critérios para a escolha do melhor armazém são conflitantes. Esta metodologia consegue de maneira simples e objetiva auxiliar na tomada de decisão em casos complexos, onde é difícil se ter uma visão ampla de todos os critérios relacionados.

\section{Referências}

ASSOCIAÇÃO BRASILEIRA DE NORMAS TÉCNICAS. ABNT. NBR 15.524-2/2008 (Sistema de Armazenagem). 2008.

ALVES, J. R. X.; ALVES, J. M. Definição de localidade para instalação industrial com o apoio do método de análise hierárquica (AHP). Production, v. 25, n. 1, p. 13-26, 2014.

ARAUJO, J. J. De; AMARAL, T. M. Application of the ELECTRE I method for selection problems involving free software development projects. GEPROS. Revista Gestão da Produção Operações e Sistemas, v. 11, n. 2, p. 121-138, 2016.

ARUEIRA, A. B. Aplicação do Método AHP para Avaliação de Transportadores, p. 71, 2014.

BAI, Y. Research on Distribution Center Layout Based on SLP. IOP Conference Series: Earth and Environmental Science, v. 330, p. 052018, 2019. 
Proposta de alteração do layout de um centro de distribuição de produtos alimentícios utilizando simulação de cenários e o método de processo de análise hierárquica (AHP)

BAKER, P.; HALIM, Z. An exploration of warehouse automation implementations: cost, service and flexibility issues. Supply Chain Management-an International Journal, v. 12, n. 2, p. 129-138, 2007.

CARDONA, L. F. et al. Detailed design of fishbone warehouse layouts with vertical travel. International Journal of Production Economics, v. 170, p. 825-837, 2015.

CHAKRABORTY, P. S.; MAJUMDER, G.; SARKAR, B. Performance measurement of Distribution Centre combining Data Envelopment Analysis and Analytic Hierarchy Process. Advances in Production Engineering \& Management, v. 6, n. 2, p. 117-128, 2011.

CUSTODIO, L.; MACHADO, R. Flexible automated warehouse: a literature review and an innovative framework. International Journal of Advanced Manufacturing Technology, v. 106, n. 1-2, p. 533-558, 2020.

DERHAMI, S.; SMITH, J. S.; GUE, K. R. A simulation-based optimization approach to design optimal layouts for block stacking warehouses. International Journal of Production Economics, p. 107525, 2019.

FABER, N.; KOSTER, M.B.M; SMIDTS, A. Organizing warehouse management. International Journal of Operations \& Production Management, v. 33, n. 9, p. 12301256, 2013.

FREITAS, A. L. P.; MARINS, C. S.; SOUZA, D. D. O. A metodologia de multicritério como ferramenta para a tomada de decisões gerenciais: um estudo de caso. GEPROS. Revista Gestão da Produção Operações e Sistemas , v. 2, n. 1, p. 51-60, 2006.

GERHARDT, T. E. Métodos de Pesquisa. Curso de Graduação Tecnológica Planejamento e Gestão para o Desenvolvimento Rural. Porto Alegre: Editora da UFRGS, 2012.

GONÇALVES, E. L. CASSEL, R. A. Proposta de melhoria do layout de um armazém de vidros automotivos. Universidade Federal do Rio Grande do Sul. Escola de Engenharia. Curso de Engenharia de Produção, 1-28, 2017. Disponível em: https://www.lume.ufrgs.br/handle/10183/170294.

GU, J., GOETSCHALCKX, M., MCGINNIS, L. F. Research on warehouse design and performance evaluation: A comprehensive review. European Journal of Operational Research, v.203, n.3, p.539-549. 2010.

GUE, K. R.; MELLER, R. D. Aisle configurationsfor unit-load warehouses. IIE Transactions (Institute of Industrial Engineers), v. 41, n. 3, p. 171-182, 2009.

GUO, Z.; ZHANG, Y. The third-party logistics performance evaluation based on the AHPPCA model. In: INTERNATIONAL CONFERENCE ON E-PRODUCT E-SERVICE AND E-ENTERTAINMENT. Anais... ICEEE2010 2010, Henan, China. Disponível em: <http://dx.doi.org/10.1109/ICEEE.2010.5661118> 
Proposta de alteração do layout de um centro de distribuição de produtos alimentícios utilizando simulação de cenários e o método de processo de análise hierárquica (AHP)

HO, W. et al. Strategic logistics outsourcing: An integrated QFD and fuzzy AHP approach. Expert Systems with Applications, v. 39, n. 12, p. 10841-10850, 2012.

HUANG, J. Y.; LIAO, J. C. A study on the performance evaluation of Computer aided picking system. Journal of Quality, v. 19, n. 2, p. 137-156, 2012.

HUERTAS, J. I.; RAMÍREZ, J. D.; SALAZAR, F. T. Layout evaluation of large capacity warehouses. Facilities, v. 25, n. 7-8, p. 259-270, 2007.

HUDSON, P. S.; HADDAD, S. R. A Importância de um Layout na Armazenagem de Produtos Acabados. Um Estudo de Caso: Diplomata S/A Industrial e Comercial. Universidade Federal do Paraná: Curitiba, 2014.

JERMSITTIPARSERT, K.; SUTDUEAN, J.; SRIYAKUL, T. Role of warehouse attributes in supply chain warehouse efficiency in Indonesia. International Journal of Innovation, Creativity and Change, v. 5, n. 2, p. 786-802, 2019.

MACHADO, R. L. P.; Boas práticas de armazenagem na indústria de alimentos. Rio de Janeiro: Embrapa Agroindústria de Alimentos, 2000. 28p.

MELO, I.H.B.S.; OLIVEIRA, M.V.S.S. Automação da Armazenagem: o caso da Multi Distribuidora. In: SIMPÓSIO DE ENGENHARIA DE PRODUÇÃO. Anais...XIII SIMPEP, Bauru, São Paulo, 2006.

MORABITO, R.; IANNONI, A. P.; Logística Agroindustrial. In: BATALHA, M. O. Gestão Agroindustrial: GEPAI: Grupo de Estudos e Pesquisas Agroindustriais. São Paulo: Atlas, 2007.

OLIVEIRA, C. A. de BELDERRAIN, M. C. N. Considerações sobre a obtenção de vetores de prioridades no AHP. I ERABIO - XXI ENDIO - XIX EPIO, POSADAS, ARGENTINA, $1-18.2008$.

ÖZCAN, T.; ÇELEBI, N.; ESNAF, Ş. Comparative analysis of multi-criteria decision making methodologies and implementation of a warehouse location selection problem. Expert Systems with Applications, v. 38, n. 8, p. 9773-9779, 2011.

PARDINI, D., MATUCK, P. J. P. Mudanças nas práticas organizacionais com a implementação do programa de gerenciamento da cadeia de suprimentos (GCS) em uma multinacional do setor siderúrgico. Revista de Gestão da Tecnologia e Sistemas de Informação, v. 9, n.1, p. 147-170, 2012.

PEINADO, J.; GRAEML, A. R. Administração da Produção: Operações industriais e de serviços. Curitiba: UnicenP, 2007.

POHL, L. M.; MELLER, R. D.; GUE, K. R. Turnover-based storage in non-traditional unitload warehouse designs. IIE Transactions (Institute of Industrial Engineers), v. 43, n. 10, p. 703-720, 2011. 
Proposta de alteração do layout de um centro de distribuição de produtos alimentícios utilizando simulação de cenários e o método de processo de análise hierárquica (AHP)

RAMOS FILHO, J. A.; ATAMANCZUK, M. J.; MARÇAL, R. F. M. Seleção de técnicas de manutenção para processo de armazenagem pelo Método de Análise Hierárquica. Revista Produção On Linea Produção On Line, , v. 10, n. 1, p. 142-166, 2010.

RIBEIRO, A. C.; COSTA, H. G. Emprego do Método de Análise Hierárquica (AHP) na distribuição de custos indiretos: Uma proposta para a pequena e média empresa. In: ENCONTRO NACIONAL DE ENGENHARIA DE PRODUÇÃO, 19, 1999, Rio de Janeiro. Anais... Rio de Janeiro: ABEPRO, 1999.

ROSA, C. R. M.; STEINER, M. T. A.; COLMENERO, J. C. Utilização de processo de análise hierárquica para definição estrutural e operacional de centros de distribuição: Uma aplicação a uma empresa do ramo alimentício. Gestao e Producao, v. 22, n. 4, p. 935-950, 2015.

ROSA, G. P.; CRACO, T.; REIS, Z. C.; NODARI, C. H. A reorganização do layout como estratégia de otimização da produção. GEPROS. Gestão da Produção, Operações e Sistemas, v. 9, n. 2, 2014.

ROY, D. et al. Performance analysis and design trade-offs in warehouses with autonomous vehicle technology. IIE Transactions, v. 44, n. 12, p. 1045-1060, 2012.

SAATY, T. L. The Analytic Hierarchy Process. New York: McGraw-Hill International, 1980.

SAATY, T. L., VARGAS, L. G. Models, methods, concepts applications of the analytic hierarchy process. Norwell: Kluwer Academic Plublishers. 2001.

SIREGAR, I., TARIGAN, U., NASUTION, T. H. Layout design in order to improve efficiency in manufacturing. IOP Conference Series: Materials Science and Engineering, $309,2018$.

SHIMIZU, T. Decisão nas Organizações. 2.ed. São Paulo: Atlas, 2006. 419p.

WANG, H.; CHEN, S.; XIE, Y. An RFID-based digital warehouse management system in the tobacco industry: a case study. International Journal of Production Research, v. 48, n. 9, p. $2513-2548,2010$.

WANG, Y. et al. Modeling of parallel movement for deep-lane unit load autonomous shuttle and stacker crane warehousing systems. Processes, v. 8, n. 1, 2020.

WEI, X. Application research of internet of things technology in China post modern logistics warehouse management based on RFID, 2012. Disponível em: https://www.researchgate.net/publication/269384389_Application_Research_of_Internet_of_ Things_Technology_in_China_Post_Modern_Logistics_Warehouse_Management_Based_on _RFID. Acesso em 10 jan. 2019.

YADAV, S.; GARG, D.; LUTHRA, S. Selection of third-party logistics services for internet 
of things-based agriculture supply chain management. International Journal of Logistics Systems and Management, v. 35, n. 2, p. 204-230, 2020.

ZHANG, G. NISHI, T., TURNER, S. D. O., OGA, K., LI, X. An integrated strategy for a production planning and warehouse layout problem: Modeling and solution approaches. Omega, v. 68, p. 85-94, 2017. 